\title{
Uncommon cutaneous manifestation of Waldmann's disease
}

\author{
Mariem Daldoul ${ }^{1}$, Mouna Korbi ${ }^{2}$, Mariem Mohamed $^{1}$, Sabeur Hammami ${ }^{1}$, and \\ Jameleddine Zili ${ }^{1}$ \\ ${ }^{1}$ Fattouma Bourguiba University Hospital of Monastir \\ ${ }^{2}$ Fattouma Bourguiba University Hospital, University of Medicine, University of Monastir
}

March 1, 2022

\begin{abstract}
Waldmann's disease (WD) is an exudative intestinal disorder that affects children or young adults, causing protein deficiency, lymphopenia and malabsorption of fat-soluble vitamins. We describe a case of a 19-year-old male with a history of WD since the age of 6 months associated with cutaneous eruption of the scrotum
\end{abstract}

\section{Hosted file}

waldmann's disease.doc available at https://authorea.com/users/461262/articles/558210uncommon-cutaneous-manifestation-of-waldmann-s-disease 


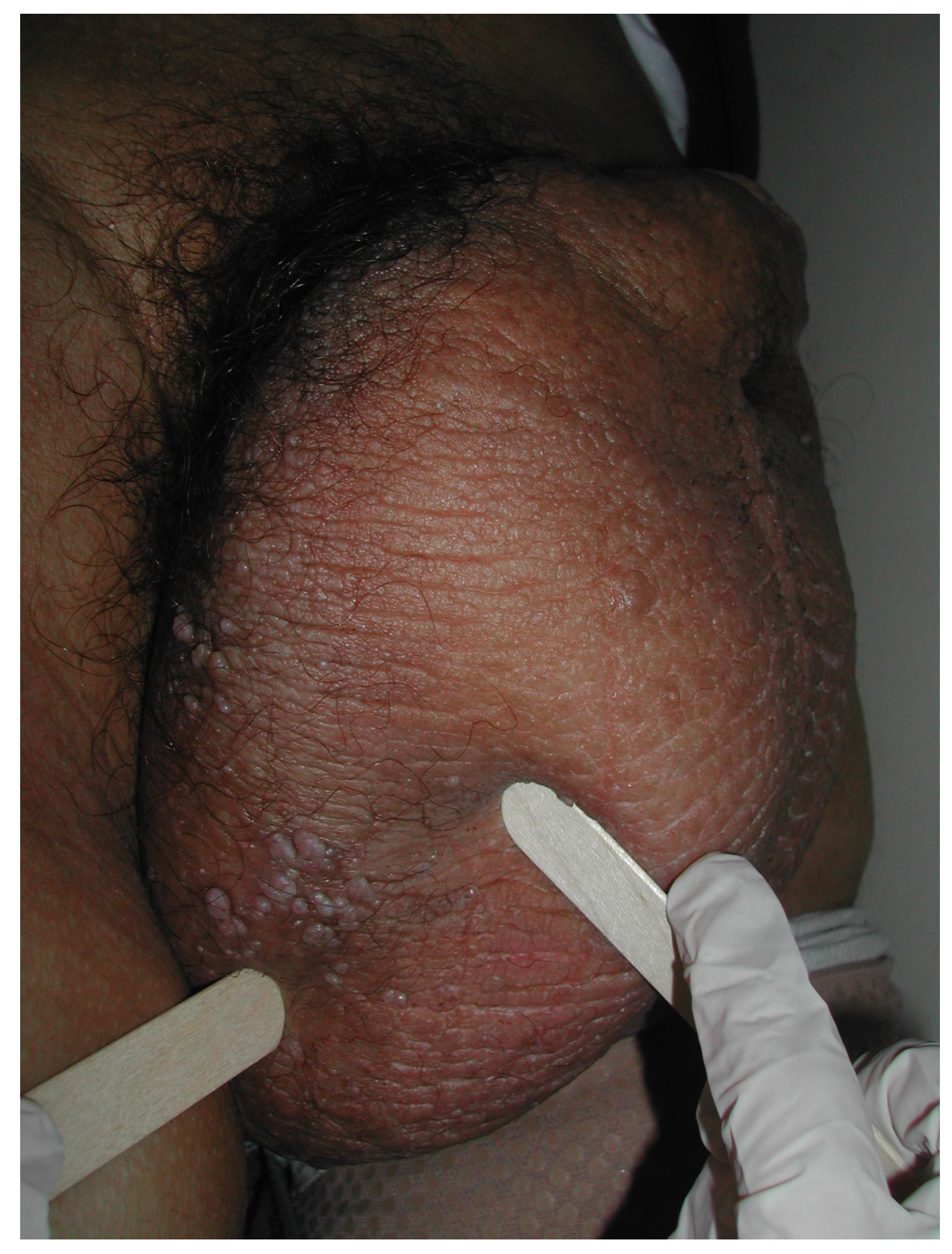

